\begin{tabular}{|l|l|l|l|l|l|l|}
\hline InterteXto & Uberaba & UFTM & $\begin{array}{l}\text { v. 3 } \\
\text { n. 1 }\end{array}$ & p. 5-23 & 2010 - jan. / jun. & ISSN 1981-0601 \\
\hline
\end{tabular}

\title{
A INTERAÇÃO PROFESSOR-ALUNOS EM SALA DE AULA E SUAS RELAÇÕES HIERÁRQUICAS: BUSCANDO COMPREENDER ESSA SITUAÇÃO A PARTIR DE SUA ORGANIZAÇÃO ENUNCIATIVA ${ }^{1}$
}

\author{
THE TEACHER-STUDENT INTERACTION IN THE CLASSROOM AND THEIR \\ RELATIONS HIERARCHIES: THYING TO UNDERSTAND THIS SITUATION FROM \\ YOUR ORGANIZATION ENUNCIATIVE
}

Adilson Ferreira de Souza²

Resumo: O objetivo deste estudo é refletir sobre a interação professor-alunos e suas relações hierárquicas na situação de sala de aula, colocando em evidência seus papéis enunciativos. Ancorado na Teoria Semiolinguística de Patrick Charaudeau, procuro, portanto, mostrar como isso se faz presente nas formas rotineiras envolvendo professor-alunos, com suas estratégias discursivas.

Palavras-chave: discurso de sala de aula; interação professor-alunos; relações hierárquicas; comportamentos enunciativos.

Abstract: The aim of this study is to discuss the teacher-students and their hierarchical relationships in the situation of the classroom, emphasizing their roles enunciatives. Anchored in Patrick Charaudeau's semiolinguistic theory, seek, therefore, show how it is present in routine forms involving teacher-students, with their discursive strategies.

Key-words: classroom discourse; teacher-student interaction; hierchical relations; enunciative conduct

\section{Introdução}

Na perspectiva de Charaudeau (1984), podemos pensar a interação como ação intercomunicativa e de caráter contratual. Uma vez contemplada a dimensão psicossocial do ato de linguagem, importa salientar que "discurso" é o lugar da encenação da significação, portanto não deve ser confundido com "texto", sendo este entendido como a materialização do ato de linguagem.

\footnotetext{
1 Neste artigo, trago contribuições de minha dissertação de mestrado, sob o título "A modalização enunciativa no discurso do professor em sala de aula: uma análise dessa prática nas $8^{a}$ s séries do ensino fundamental" Belo Horizonte/ FALE/UFMG, 2008. 134f.

2 Possui graduação em Letras (PUC-MINAS) e Mestrado em Estudos Linguísticos pela Universidade Federal de Minas Gerais - Faculdade de Letras.
} 


\begin{tabular}{|l|l|l|l|l|l|l|}
\hline InterteXto & Uberaba & UFTM & $\begin{array}{l}\text { v. 3 } \\
\text { n. } 1\end{array}$ & p. 5-23 & 2010 - jan. / jun. & ISSN 1981-0601 \\
\hline
\end{tabular}

Segundo ele, a aplicação do termo "discurso" nos é apresentada em dois sentidos, estando, portanto, relacionada:

1. ao fenômeno da encenação do ato de linguagem, que compreende o circuito externo (dimensão situacional), representado pelo lugar do Fazer psicossocial; e o circuito interno (dimensão comunicacional), representado pelo lugar de organização do Dizer.

2. a um conjunto de saberes partilhados, construídos pelos indivíduos de um grupo social.

Com interesse voltado para o sentido social e os efeitos da linguagem em uso, a Análise do Discurso analisa a matéria linguística não como uma entidade abstrata, mas como fato social. Por essa razão, consideramos a Teoria Semiolinguística, de Patrick Charaudeau, como valioso instrumento em Análise do Discurso, já que privilegia a ocorrência dos atos de linguagem em determinadas situações interlocutivas. Ela oferece metodologia de análise que propicia a consideração das significações psicossociais envolvidas nos discursos analisados e permite estabelecer relações entre as características internas das trocas comunicativas e as hipóteses mais externas sobre os comportamentos socioculturais dos grupos a que pertencem os sujeitos envolvidos.

Uma vez que vamos abordar a situação de comunicação de sala de aula, importa dizer que a orientação do ato de linguagem é determinada pelas visadas, "que correspondem a uma intecionalidade psico-sócio-discursiva que determina a expectativa do ato de linguagem do sujeito falante e, por conseguinte, da própria troca linguageira" (CHARAUDEAU, 2004). No contexto de sala de aula, teremos, portanto, como visadas principais, a visada de instrução: o sujeito (professor) quer "fazer saber e ele se encontra ao mesmo tempo em posição de legitimidade para fazer saber e de competência de saberfazer-saber"; e uma visada de informação: o sujeito quer "fazer saber" e ele 


\begin{tabular}{|l|l|l|l|l|l|l|}
\hline InterteXto & Uberaba & UFTM & $\begin{array}{l}\text { v. 3 } \\
\text { n. 1 }\end{array}$ & p. 5-23 & 2010 - jan. / jun. & ISSN 1981-0601 \\
\hline
\end{tabular}

está em sua posição de saber. O destinatário (aluno) se encontra na posição de "não saber" e de "dever saber" alguma coisa, os saberes escolares. A transmissão de saberes, efetivada pelas práticas de ensino em sala de aula, passa por essa duas principais visadas, o que não exclui a possibilidade de outras que podem talvez ser convocadas (incitação, sedução, etc.).

É importante entender que essas visadas determinam a orientação do ato de linguagem como ato de comunicação em função da relação que o sujeito falante deseja instaurar diante de seu destinatário. O que dizer e o que fazer fazem parte dessa relação contratual existente entre tais parceiros, como a seguir podemos ver:

\section{A enunciação didática:}

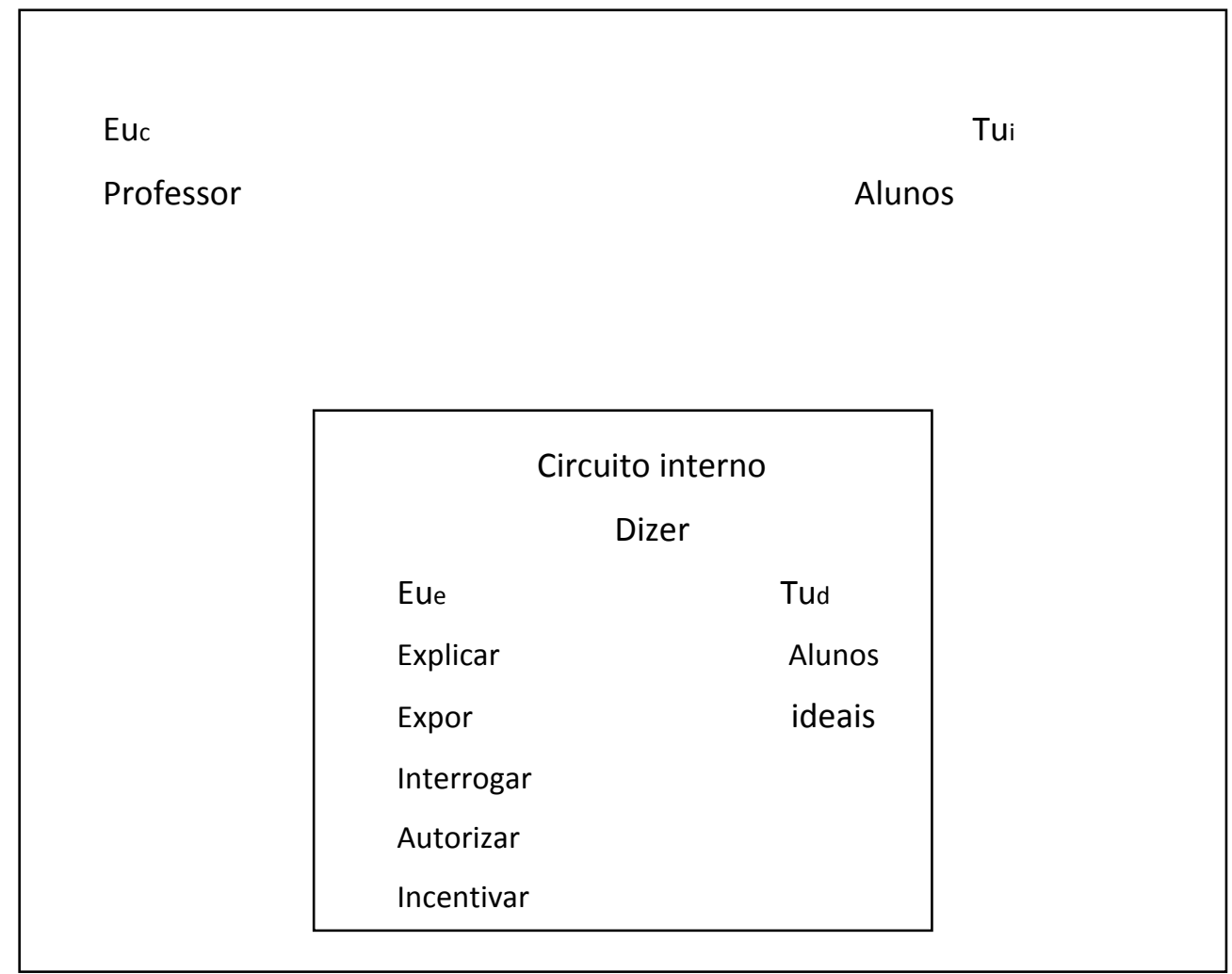

Como podemos ver, o Circuito Externo diz respeito aos seres empíricos, pessoas reais, que desempenham o papel de professor e alunos. Já o Circuito Interno é o espaço das idealizações, das representações psico-sócio-históricas 


\begin{tabular}{|l|l|l|l|l|l|l|}
\hline InterteXto & Uberaba & UFTM & $\begin{array}{l}\text { v. 3 } \\
\text { n. 1 }\end{array}$ & p. 5-23 & 2010 - jan. / jun. & ISSN 1981-0601 \\
\hline
\end{tabular}

dos sujeitos falantes envolvidos na comunicação. A partir desse quadro, tentaremos mostrar alguns aspectos ligados à questão de contrato e da representação de papéis exigida na sala de aula, ou seja, da identidade dos parceiros (professor/ alunos). O Eu e o Tu são atores envolvidos na comunicação educativa, numa relação assimétrica em que o professor tem o papel de ensinar, avaliar e captar, enquanto o aluno tem o papel de reconhecer o seu não saber, ou seja, a sua condição de aprendiz. O circuito externo diz respeito aos seres empíricos, pessoas reais que desempenham o papel de professor e aluno; o circuito interno, por sua vez, corresponde ao espaço das idealizações, das representações psico-sócio-históricas dos sujeitos falantes envolvidos na comunicação.

Quando falamos de comunicação humana, na verdade, estamos remetendo a relações que são construídas dentro de um determinado contexto. $\mathrm{Na}$ situação de sala de aula, por exemplo, existem relações entre professor e alunos, cujos papéis são institucionalmente pré-estabelecidos. $\mathrm{Na}$ instituição escolar, professores e alunos estão imbuídos de papéis legitimados institucionalmente, mas não há simetria entre eles. Sabemos que o professor ocupa uma posição enunciativa que deve ser reconhecida pelo aluno, por exemplo, uma posição enunciativa de quem pode e deve ensinar, afirmar coisas, autorizar, avaliar, interrogar. Essa situação lhe permite orientar o trabalho que vai ser desenvolvido em classe, ministrar os conteúdos, responder às dúvidas de alunos, animar a aula, realizar avaliações, etc. Pensando nas ações que são desenvolvidas no espaço de sala de aula, gostaria de abordar um importante aspecto que diz respeito ao gênero, já que a aula assim se constitui. Quanto ao gênero, Emediato (2003, p.71) vai dizer que

O gênero, na verdade, corresponderia a uma série de categorizações inter-relacionadas: categorização dos domínios de prática social, sub-categorização desses domínios em situações de comunicação, categorização das formas semiolinguísticas mais adaptadas e pertinentes às categorizações anteriores, categorização de regularidades e de 


\begin{tabular}{|l|l|l|l|l|l|l|}
\hline InterteXto & Uberaba & UFTM & $\begin{array}{l}\text { v. 3 } \\
\text { n. 1 }\end{array}$ & p. 5-23 & 2010 - jan. / jun. & ISSN 1981-0601 \\
\hline
\end{tabular}

variantes textuais.

Numa tentativa de visualizar a aula dentro desse processo de categorização, tendo em vista as ações dos atores envolvidos na comunicação didática (professor / alunos), teríamos, então, como representação dos condicionamentos impostos pela situação de comunicação didática, o seguinte quadro:

QUADRO 1 - Os condicionamentos impostos pela situação de comunicação

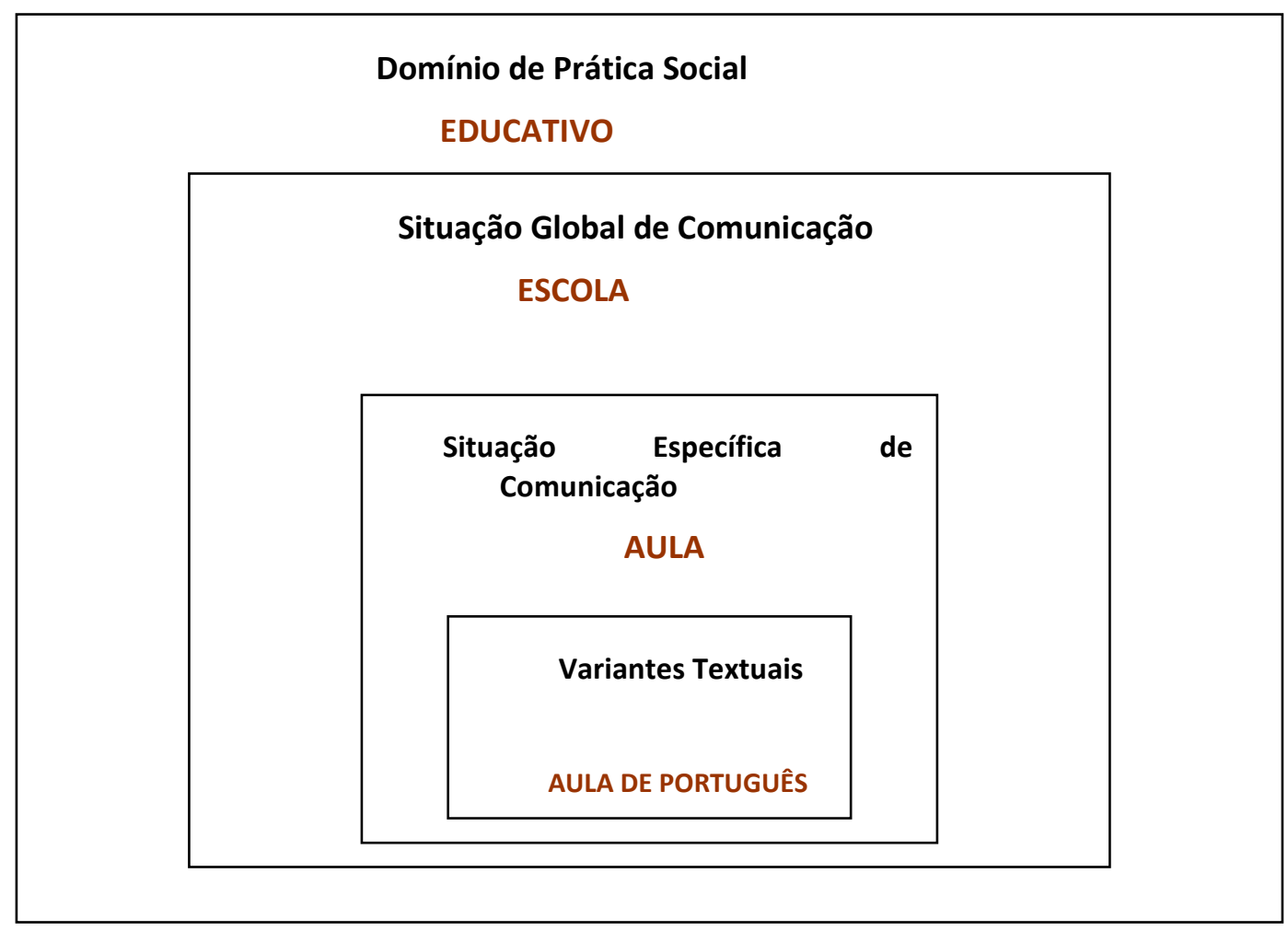

Com maior freqüência, a aula articula-se com eventos de interação que objetivam introduzir o sujeito em uma certa área de conhecimentos. É através dela, mas não somente, que o discurso didático se atualiza. Ele tem a função de introduzir o sujeito no campo dos saberes e das práticas escolares, uma vez que sua característica mais importante é "fazer aprender". Esse tipo de discurso está presente em suas manifestações escritas, como os manuais didáticos, e, em suas manifestações orais, nas práticas interativas em sala de 


\begin{tabular}{|l|l|l|l|l|l|l|}
\hline InterteXto & Uberaba & UFTM & $\begin{array}{l}\text { v. 3 } \\
\text { n. } 1\end{array}$ & p. 5-23 & 2010 - jan. / jun. & ISSN 1981-0601 \\
\hline
\end{tabular}

aula (BEACCO \& MOIRAND, 1995), vistas aqui com maior interesse, uma vez que o discurso do professor é o ponto crucial deste artigo. E uma das formas de apreender esse discurso é através da "fala" do professor.

Essa reflexão ainda pode ser enriquecida, se considerarmos os componentes de uma situação de comunicação, a partir dos quais veremos como se dão as relações interpessoais. Pois, como disse Charaudeau (1992), essa relação se define, segundo:

a) As características físicas: a disposição dos falantes (interação face-aface ou não); número de participantes; proximidade ou distância dos parceiros; o canal de transmissão (oral ou gráfico; direto ou indireto); outros códigos semióticos utilizados (imagem, sinal, gesto, ...).

b) As características identitárias dos participantes: sociais (idade, sexo, raça, classe), profissionais (médico, escrivão, professor, etc.), psicológicas (inquieto, nervoso, sereno, espontâneo, amável, agressivo,...) e relacionais (os participantes entram em contato pela primeira vez ou não; eles se conhecem? eles têm relação familiar ou não?).

c) As características contratuais: contrato de troca e não-troca; as situações de comunicação (interlocutiva); os rituais de abordagem comunicativa.

Nesse sentido, Vion (1995) vai dizer em seu artigo La gestion pluridimensionnelle du dialogue, que as relações institucionais contribuem para definir o quadro social do encontro e justifica uma tipologia das interações. Podemos então dizer que as interações, que se dão no cotidiano de sala de aula, são determinadas por esse quadro institucional, a que chamamos de escola. Na perspectiva desse autor, podemos compreender esse quadro, levando-se em conta: a natureza da situação de comunicação, na qual os atores (professor/alunos) estão engajados; os tipos de textos que são 


\begin{tabular}{|l|l|l|l|l|l|l|}
\hline InterteXto & Uberaba & UFTM & $\begin{array}{l}\text { v. 3 } \\
\text { n. } 1\end{array}$ & p. 5-23 & 2010 - jan. / jun. & ISSN 1981-0601 \\
\hline
\end{tabular}

mobilizados; a natureza da relação social entre os contractantes; os lugares discursivos que eles ocupam na interação; os lugares que se constroem; as estratégias de posicionamento e de comunicação que os interlocutores se esforçam em coordenar.

\section{A sala de aula e as representações hierárquicas}

Quando falamos de lugares e papéis, somos levados a refletir sobre as representações hierárquicas e a natureza do contrato de sala de aula, como assinala Ricoeur (1969, p. 53-54 apud AQUINO, 1996, p. 39-40):

Esta relação ('de ensino') é difícil, sem dúvida uma das mais difíceis de ser exercida em nossa sociedade. É primeiramente uma relação assimétrica, em que a carga de competência e experiência dá licença, da parte do ensinante, ao exercício de um domínio que é muito fácil de consagrar por meio de instituições hierárquicas e coercitivas. A tendência espontânea do ensinante é pensar que o ensinando não sabe nada, que aprender é passar da ignorância ao saber, e que esta passagem está em poder do mestre. Ora, o ensinando traz alguma coisa: aptidões e gostos, saberes anteriores e saberes paralelos e, sobretudo, um projeto de realização pessoal que não será, senão parcialmente, preenchido pela instrução, pela preparação profissional ou pela aquisição de uma cultura para os momentos de lazer. O ensino é de fato uma relação assimétrica, mas não em sentido único. $O$ contrato que liga o professor ao aluno comporta uma reciprocidade essencial, que é o princípio e a base de uma colaboração. Contribuindo para a realização parcial do projeto do aluno, o professor continua a aprender; ele é verdadeiramente ensinado pelos seus alunos e, assim, recebe deles ocasião e permissão de realizar o seu próprio projeto de conhecimento e de saber. Eis por que é preciso dizer - parafraseando Aristóteles - que o ensino é ato comum do professor e do aluno.

Vemos, então, que a situação escolar é marcada pela assimetria das relações, regulada pelas cláusulas do contrato de comunicação de sala de aula. O autor evoca a cooperação e a reciprocidade como atributos essenciais 


\begin{tabular}{|l|l|l|l|l|l|l|}
\hline InterteXto & Uberaba & UFTM & $\begin{array}{l}\text { v. 3 } \\
\text { n. } 1\end{array}$ & p. 5-23 & 2010 - jan. / jun. & ISSN 1981-0601 \\
\hline
\end{tabular}

nesta relação, mas dificultada pela assimetria constitucional dos lugares institucionais de professor e aluno. A ideia de um aluno que se encontra em estado de "ignorância", de alguém que deve se reconhecer como aprendiz, contrapõe a de alguém que traz consigo saberes anteriores e prévios de sua experiência quotidiana. Os projetos de realização pessoal do aluno não se cruzam com aqueles do professor. Nesse desencontro de demandas, esta difícil relação é marcada pela regulação das relações de poder.

Nas palavras de Charaudeau (1983), em uma sociedade são exercidas as estratégias de poder que são o resultado de um jogo do ser e do parecer entre o estatuto social dos sujeitos do circuito comunicativo (EUc/TUi) e o estatuto linguageiro dos sujeitos que constroem a manifestação linguageira (JEe/Tud).

Nesse particular, Bourdieu (1996), em sua obra intitulada "Economia das trocas lingüísticas", ao analisar o papel da linguagem nas relações sociais, explica essas relações como forças simbólicas que determinam o poder e o domínio que alguns falantes exercem sobre os outros e, ainda, porque determinados produtos lingüísticos recebem mais valor do que outros. Assim, nos eventos de interação, as forças simbólicas definem quem pode falar, a quem e como, atribuindo, portanto, valor e poder à linguagem de um interlocutor em detrimento de outro.

Nesse sentido, Gnerre (1998), nos fala de uma linguagem que, além de veicular informações, tem como objetivo principal comunicar ao ouvinte a posição que o falante ocupa ou acredita que ocupa na sociedade em que vive. Significa dizer que as pessoas falam, seja para serem "ouvidas", seja para serem respeitadas ou, então, para exercer influência no ambiente em que realizam os atos lingüísticos.

Continuando essa reflexão, Michel Foucault, em sua obra Microphysique du pouvoir, propõe uma leitura do poder em termos de forças múltiplas, relações de amplitude microfisiológica estruturando as atividades dos homens em sociedade. Para ele, o poder está presente em todas as instituições tais 


\begin{tabular}{|l|l|l|l|l|l|l|}
\hline InterteXto & Uberaba & UFTM & $\begin{array}{l}\text { v. 3 } \\
\text { n. 1 }\end{array}$ & p. 5-23 & 2010 - jan. / jun. & ISSN 1981-0601 \\
\hline
\end{tabular}

como a penitenciária, a escola, a usina, a família. Ele concebe o poder como atributo exclusivo de um homem, de um estado, de uma classe. Segundo este autor, o poder é algo difuso e não localizado em lugar preciso (FOUCAULT, apud LEFRANC, 1994). Tomando por base essas considerações, podemos, então, refletir sobre o modo como se dá a regulação das relações de poder no espaço de sala de aula, onde a disciplina e a coerção aparecem, com frequência, como mecanismo de controle, o que justifica a assimetria da relação professor/alunos no domínio educativo, legitimada institucionalmente.

Vimos, então, que as relações de poder estabelecidas entre os agentes (profissionais de educação e aprendizes) são legitimadas pela instituição, constituída pela sociedade, que aceita e aprova tais relações.

$\mathrm{Na}$ escola, o quadro da interação é definido pela situação de ensino que envolve professores e alunos numa relação, o que significa dizer que a instituição determina o modo como a interação se estabelece entre sujeitos falantes, já que seus papéis são legitimados institucionalmente. A propósito dessa legitimidade, Aquino (1996, p. 50) vai dizer que

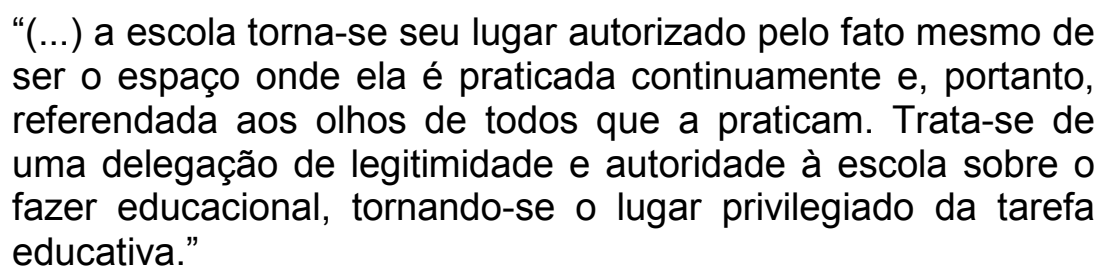

Como podemos ver, a escola dá legitimidade e autoridade aos agentes de educação (e neste caso, estamos pensando especificamente no professor), que se encontram numa posição privilegiada em relação aos alunos. Vimos então que as relações de poder se efetivam em âmbito institucional, como, a seguir, atesta Furlani (1988, p. 19):

(...) O aspecto institucional é aqui primordial, já que a relação estabelecida entre professor e aluno é possível porque tem, atrás de si, uma instituição formal, constituída pela sociedade que, de modo geral, aprova e aceita as relações de poder nela existentes, as quais, assim, se constituem em autoridade. 


\begin{tabular}{|l|l|l|l|l|l|l|}
\hline InterteXto & Uberaba & UFTM & $\begin{array}{l}\text { v. 3 } \\
\text { n. } 1\end{array}$ & p. 5-23 & 2010 - jan. / jun. & ISSN 1981-0601 \\
\hline
\end{tabular}

Desse modo, a relação professor-aluno, sob alguns aspectos, é a concretização de uma instituição de nossa cultura, da mesma forma que o é a autoridade que tem o professor, como agente responsável, diante do sistema social mais amplo, pelo desempenho do grupo-classe.

Como vimos, essa autora, também nos mostra como a estrutura de autoridade no processo de ensino-aprendizagem tem respaldo institucional, a julgar pelo tipo de relação existente entre professor e alunos, revelador de uma representação, histórica e culturalmente estabilizada, dos profissionais de educação e aprendizes.

\section{Modalização enunciativa, atos locutivos e modalidades enunciativas}

Uma investigação da modalização no discurso didático pode ajudar-nos a explicar a inter-relação entre a autoridade e o poder do sujeito falante em relação a seu interlocutor, e a exploração de significados modais para propósitos didáticos. Tentar entender isso na situação de sala de aula nos levará, com efeito, a uma compreensão dos propósitos de manipulação da língua, quando se trata de usar a modalização, que implica diferentes modos do sujeito falante se posicionar em relação a seu interlocutor.

Charaudeau (1992), em seu capítulo sobre os componentes do aparelho enunciativo, descreve a modalidade ou a modalização do enunciado, em termos de comportamento "alocutivo", "elocutivo" e "delocutivo". De acordo com este autor:

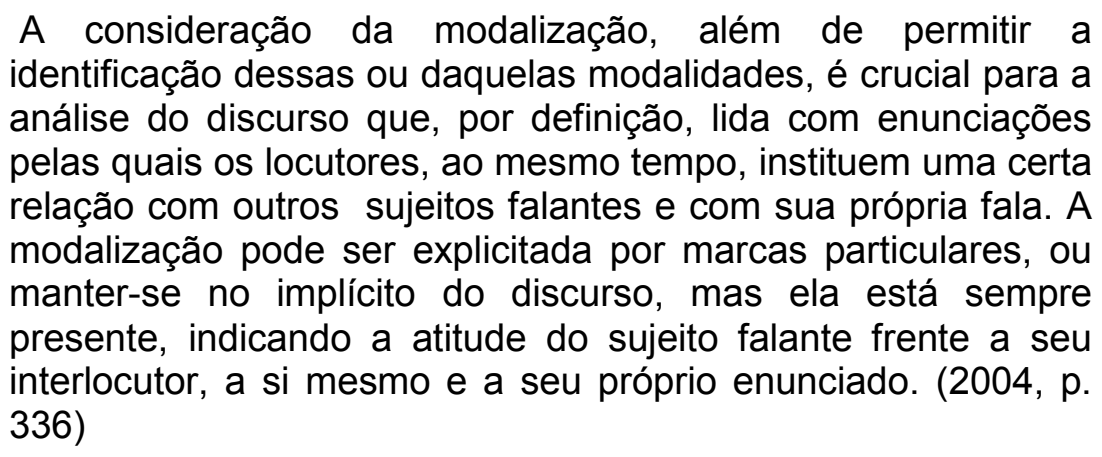

Assim, vemos que o sujeito falante pode manifestar, de forma implícita 


\begin{tabular}{|l|l|l|l|l|l|l|}
\hline InterteXto & Uberaba & UFTM & $\begin{array}{l}\text { v. 3 } \\
\text { n. 1 }\end{array}$ & p. 5-23 & 2010 - jan. / jun. & ISSN 1981-0601 \\
\hline
\end{tabular}

ou explícita, diante de seu interlocutor, adesão ao que diz ou também pode não assumir totalmente suas proposições, já que o que, de fato, estão em jogo são seus interesses e objetivos. Na verdade, o sujeito falante para seduzir o seu interlocutor pode fazer uso de algumas estratégias lingüísticas, como, por exemplo, os modalizadores.

Charaudeau (1992) define a modalização como o posicionamento do falante em relação a seu interlocutor. De acordo com esse autor, a modalização não constitui o todo da enunciação, pois ela é um fenômeno complexo que testemunha o modo como o sujeito falante se apropria da língua, para organizar os discursos. Ela é composta de um certo número de atos enunciativos que correspondem a uma posição particular, e a um comportamento particular, do locutor em seu ato de locução. Ele relaciona as modalidades com os atos locutivos.

Esse autor, ainda, aponta os problemas que comportam incluir a modalização entre as categorias formais, e considera que se trata de uma categoria conceitual. Para isso, vai dizer que (i) não se deve classificar as modalidades segundo as formas verbais e adverbiais, já que no uso linguageiro podem remeter a diferentes modalidades. (ii) as marcas lingüísticas não são monossêmicas, já que uma mesma marca pode recobrir diferentes sentidos. Por exemplo, o verbo querer pode exprimir um desejo, uma ordem, uma demanda, de acordo com o contexto. (iii) a modalização pode não estar expressa no texto por meio de uma marca lingüística, mas por uma organização do conjunto do enunciado. A polimorfia linguística é visível nas múltiplas possibilidades que oferecem a língua para expressar, por exemplo, uma ordem: Ordeno-te que vá! Fora, é uma ordem! "Fora!" (mais o gesto do dito). (iiii) a modalização encontra-se no implícito do discurso. Significa dizer que a modalização pode não estar expressa por alguma marca lingüística, mas manifestar-se na organização do enunciado, juntamente com outros índices verbais e para-verbais (entonação, gestos, olhar, pontuação) e com as particularidades da situação de comunicação, que indicam uma modalidade 


\begin{tabular}{|l|l|l|l|l|l|l|}
\hline InterteXto & Uberaba & UFTM & $\begin{array}{l}\text { v. 3 } \\
\text { n. 1 }\end{array}$ & p. 5-23 & 2010 - jan. / jun. & ISSN 1981-0601 \\
\hline
\end{tabular}

enunciativa concreta.

Uma vez feitas essas considerações, destacamos os seguintes atos locutivos e, depois, apresentamos o quadro em que Charaudeau (1992) nos apresenta a distribuição dos atos enunciativos. Sendo assim, os atos locutivos se dividem em:

Ato Alocutivo: o locutor implica o seu interlocutor no ato de enunciação. As formas lingüísticas, como os pronomes (tu, você), substantivo próprio ou comum, que identifica o interlocutor, bem como o estatuto da frase (interrogativa ou imperativa) expressa esse tipo de ato: Ex: questionar, advertir, sugerir, julgar.

Ato Elocutivo: o locutor se posiciona em relação a si mesmo em seu ato de enunciação, sem envolver o outro, seu interlocutor. As formas lingüísticas que identificam esse ato são os pronomes de $1^{\text {a }}$ pessoa (eu, nós), o substantivo próprio ou comum, referindo-se ao locutor e ao estatuto da frase (exclamativa).

Ato Delocutivo: o enunciado impõe-se por si mesmo, deixando o locutor e o interlocutor como se estivesse ausente do ato enunciativo. Esse tipo de ato aparece sob a forma impessoal ou refere-se à $3^{a}$ pessoa. Ele reúne como modalidades a asserção e o discurso relatado.

Tendo em vista o quadro que se segue, vamos propor uma descrição dos modos de enunciação didática, procurando relacionar os comportamentos enunciativos com as representações que circulam no espaço escolar.

QUADRO 1 - Quadro enunciativo de Charaudeau (adaptação):

\begin{tabular}{|c|c|c|}
\hline \multicolumn{3}{|c|}{ MODALIZAÇÃO ENUNCIATIVA } \\
\hline ATOS ENUNCIATIVOS & MODALIDADES & ESPECIFIC. ENUNCIATIVAS \\
\hline \multirow[b]{3}{*}{ ALOCUTIVO } & Interpelação & \multirow{5}{*}{$\begin{array}{l}\text { Relação de conhecimento social/ } \\
\text { afetivo } \\
\text { (Relação de força) } \\
\text { Positivo ou negativo }\end{array}$} \\
\hline & Injunção & \\
\hline & Autorização & \\
\hline Voltado para Tu & Advertência & \\
\hline Relação & Ordem & \\
\hline
\end{tabular}




\begin{tabular}{|l|l|l|l|l|l|l|}
\hline InterteXto & Uberaba & UFTM & $\begin{array}{l}\text { v. 3 } \\
\text { n. 1 }\end{array}$ & p. 5-23 & 2010 - jan. / jun. & ISSN 1981-0601 \\
\hline
\end{tabular}

\begin{tabular}{|c|c|c|}
\hline \multirow[t]{5}{*}{ influência. } & Julgamento & \\
\hline & Sugestão/Proposição & \\
\hline & Interrogação & \multirow{3}{*}{ Demanda de informação } \\
\hline & Requerimento & \\
\hline & Solicitação & \\
\hline \multirow{12}{*}{$\begin{array}{l}\text { ELOCUTIVO } \\
\text { - } \quad \text { "eu" no } \\
\text { discurso }\end{array}$} & Confirmação & \multirow[t]{2}{*}{ Modos de saber } \\
\hline & $\begin{array}{l}\text { O saber/ A ignorância/ } \\
\text { Constatação }\end{array}$ & \\
\hline & A opinião & \multirow[t]{2}{*}{ Avaliação } \\
\hline & A apreciação & \\
\hline & A Proclamação & Decisão \\
\hline & A obrigação & \multirow{3}{*}{ Motivação } \\
\hline & Querer & \\
\hline & A possibilidade & \\
\hline & A promessa & \multirow{4}{*}{ Engajamento } \\
\hline & A aceitação / refutação & \\
\hline & O acordo/ desacordo & \\
\hline & A declaração & \\
\hline DELOCUTIVO & Asserção & \multirow[t]{2}{*}{ Evidência / Probabilidade } \\
\hline $\begin{array}{l}\text { "Ninguém assume a } \\
\text { palavra" }\end{array}$ & $\begin{array}{l}\text { (Como se impõe o } \\
\text { mundo) }\end{array}$ & \\
\hline $\begin{array}{l}\text { (Testemunho sobre o } \\
\text { mundo) }\end{array}$ & $\begin{array}{l}\text { Discurso relatado } \\
\text { (Como fala o outro) }\end{array}$ & $\begin{array}{l}\text { Citado, integrado, narrativizado } \\
\text { alusivo }\end{array}$ \\
\hline
\end{tabular}

Quadro extraído e adaptado de Charaudeau (1992) citado por Emediato (2006)

A análise das formas enunciativas, como nos assegura Emediato (2006), pode nos ajudar a compreender melhor as estratégias de regulação, bem como as representações psico-sócio-comunicativas que se encontram subjacentes às práticas educativas. No espaço escolar, a atuação do professor é marcada por aspectos expressivos que revelam a assimetria da relação.

A análise das formas de interação na sala de aula nos dá pistas sobre as estratégias colocadas em prática por professores no interior de uma relação contratual com os alunos. Há um lugar social de ancoragem de toda atividade discursiva: um espaço de posicionamentos que se relaciona aos sistemas de valores que circulam na sociedade, e outro espaço de condicionamentos, 


\begin{tabular}{|l|l|l|l|l|l|l|}
\hline InterteXto & Uberaba & UFTM & $\begin{array}{l}\text { v. 3 } \\
\text { n. } 1\end{array}$ & p. 5-23 & 2010 - jan. / jun. & ISSN 1981-0601 \\
\hline
\end{tabular}

comunicacionais, no que se refere aos diferentes formatos de comunicação, e enunciativos, no que se refere às diferentes maneiras de falar em cada situação de comunicação (CHARAUDEAU, 2004, apud EMEDIATO, 2006).

Essa discussão nos remete a uma idéia do papel que o professor ocupa e da autoridade que lhe é garantida pela escola. Essas posições resultam da relação saber/não saber e poder/ não poder.

\section{Os comportamentos enunciativos em sala de aula}

Como o ponto central dessa discussão é a modalização enunciativa, relacionada aos comportamentos enunciativos e às representações que circulam no espaço escolar, trazemos, a seguir, algumas ocorrências de interação que colocam em evidência essa situação de comunicação didática. Além disso, apresentamos as normas ${ }^{3}$ adotadas para transcrição das ocorrências de interação em curso.

Este trecho, por exemplo, se refere ao início de uma aula, quando a professora, após chegar na sala de aula, a ordem (modalidade de injunção) aparece como uma das estratégias voltadas para o fazer-fazer, ou seja, as atividades de controle das ações implementadas nos aprendizes, evidenciada

${ }^{3}$ Normas adotadas para transcrição (fundamentadas nas normas de Castilho, A. \& Preti, D. (Orgs.) A linguagem falada culta na cidade de São Paulo: materiais para seu estudo. São Paulo, TAQ, 1986):

a) Incompreensão de palavras ou segmentos:

[inaudível]

b) Truncamento:

c) Alongamento de vogal ou consoante:

d) Superposição, simultaneidade de vozes:

// $\operatorname{xxxx~//~}$

e) Comentários descritivos do transcritor:

$\{x x x x\}$

f) Qualquer pausa:

g) Citações literais:

h) Entonação enfática:

MAIÚSCULAS

Observações complementares: Profa indica que as intervenções são feitas pela professora; Als indica que vários alunos falam ao mesmo tempo; Aluna ou Aluno indica a intervenção de aluna ou aluno; Ev. significa evento, para localizar o enunciado no anexo. 


\begin{tabular}{|l|l|l|l|l|l|l|}
\hline InterteXto & Uberaba & UFTM & $\begin{array}{l}\text { v. 3 } \\
\text { n. } 1\end{array}$ & p. 5-23 & 2010 - jan. / jun. & ISSN 1981-0601 \\
\hline
\end{tabular}

nas seguintes sequências (23), (28) e (30). Fato que nos pareceria curioso é o aluno dar ordem ao professor, o que parece não corresponder ao estatuto sócio-profissional de aluno.

22 Als: [falas simultâneas e movimentos na sala)

23 Profa: Júlio, caderno aberto... agenda, caderno de português... (Alocutivo de ordem)

24 Aluno: Aonde, professora?

25 Profa: Gen::te,

26 Aluno: Bom dia, minha gente!

27 Aluna: fessora, que que a gente vai fazer?

28 Profa: Todos virados pra fren::te... postura que ainda está faltando ali no cantinho ... Lá debaixo da lateral... Estou esperando TODO mundo virado pra FRENte... Não quero ninguém sentado de lado. (Alocutivo de ordem)

29 Aluno: Ah, professora!

30 Profa: Nenhum sentado de ??? Estou mandando. ! (Alocutivo de ordem)

31 Aluno: Vai fazer bagunça.

32 Profa: Ainda dá pra ouvir ??? Pronto para daqui a pouquinho no colégio. \{barulhos\}

33 Profa: Ok, Eduardo.

// Aluno rindo//

É importante frisar que os atos alocutivos de advertência permitem ao professor colocar em evidência a sua autoridade em relação aos comportamentos e atitudes desejadas por ele no processo de ensino/aprendizagem, manter a disciplina, etc. Além disso, podemos considerálas, até certo ponto, inerentes à pratica educativa, tendo em vista as necessidades e objetivos de ensino.

No caso da advertência, destacamos uma situação em que a professora ameaça os alunos de dar-lhes falta caso não copiem as perguntas relacionadas ao texto lido em sala de aula, como podemos observar nas sequências abaixo (210) a (213) e (222) a (224):

210 Aluno: Não vou copiar a pergunta, não.

211 Profa: "Os dois..." Vão copiar os [inaudível]. Então "Os dois primeiros/" 


\begin{tabular}{|l|l|l|l|l|l|l|}
\hline InterteXto & Uberaba & UFTM & $\begin{array}{l}\text { v. 3 } \\
\text { n. } 1\end{array}$ & p. 5-23 & 2010 - jan. / jun. & ISSN 1981-0601 \\
\hline
\end{tabular}

212 Aluno: Eu vou copiar a pergunta?

213 Profa: Ah, claro, uai! Quem não copiar, eu vou dar falta, tá? (Alocutivo: advertência)

222 Profa: Eu quero ver quem está/ quem não está copiando, viu.

223 Aluno: Gros-so.

224 Profa: Na chamada eu vou dar falta pra ele. xeu ver [inaudível] (Alocutivo: advertência)

Observamos também, na sequência (188) a (191), a ocorrência da modalidade de injunção, através da ordem, que é legítima do professor e pouco esperada de um aluno. Trata-se de um comportamento enunciativo previsto e compatível com o papel de ensinante. Como o professor detém a iniciativa quase total sobre as modalidades de injunção (EMEDIATO, 2006), ilustramos essa situação a partir do trecho que se segue:

188 Profa: A partir/ ô pessoal , ago::ra, outro está louco pra ouvir... Oi! ... Ago::ra ... vocês vão se imaginaR ... (Alocutivo: ordem)

189 Als: [conversas paralelas]

190 Aluna: Atenção, qual desses dois vai ??? ou!

191 Profa: Vocês vão imaginar que vocês entraram numa sala de bate-papo, tá::? e vocês vão/ vocês irão elaboRAR // um anúncio // (Alocutivo: ordem)

Assinalamos, ainda, a incidência dos atos alocutivos de ordem nas situações escolares, a exemplo do evento (72), em que a professora exige de seus alunos o silêncio e, ainda, proíbe um deles de sair da sala.

72 Profa: SilENcio. Agora [inaudível]. (Alocutivo: ordem) Ô, gente, agora cê não vai não. Vai quando terminar essa aula aqui ... tá? (Alocutivo: proibição) Você tá passando mal? Hein? (Alocutivo: interrogação)

73 Aluno: Tô passando mal, fessora.

74 Profa: [inaudível] a aula como funciona, né? Então, vamos lá. O texto é... qual que é o nome do texto aí, gente? (Alocutivo: interrogação de controle)

75 Als: "Droga: essa viagem tem volta"

Vimos que a ordem aparece com maior incidência, acompanhada de outros atos como o pedido, a interrogação de controle e a proibição. 


\begin{tabular}{|l|l|l|l|l|l|l|}
\hline InterteXto & Uberaba & UFTM & $\begin{array}{l}\text { v. 3 } \\
\text { n. } 1\end{array}$ & p. 5-23 & 2010 - jan. / jun. & ISSN 1981-0601 \\
\hline
\end{tabular}

Salientamos que os atos alocutivos de ordem são voltados para o fazerfazer, ou seja, para as atividades de controle das ações a serem implementadas nos aprendizes. Outra estratégia de controle são as interrogações, que constituem estratégias de aferição e diagnose, correspondendo ao que a literatura pedagógica chama de avaliação diagnóstica. Elas controlam o processo de aquisição de saberes por parte do aluno e permitem ao professor desenvolver estratégias de ensino pela retroinformação.

\section{Considerações finais}

O que evidenciamos nesta reflexão mostra que os procedimentos de modalização têm um papel regulador nas relações que se estabelecem entre os participantes na interlocução. Vimos, a partir de alguns exemplos, uma amostra de algumas modalidades enunciativas, que são iniciativas quase exclusivas do professor, pois, no plano dos atos alocutivos, a injunção (ordem), a advertência e as interrogações de controle correspondem a ações próprias do papel de ensinante, ou seja, de quem tem o poder sobre a palavra na sala de aula. Ao pensar na relação professor/alunos em termos de contrato, devemos levar em conta que as práticas de ensino-aprendizagem se inscrevem no interior de um contrato didático, que vai dizer o que é cabível a cada pessoa envolvida na situação de comunicação didática.

Além disso, lembramos que, de acordo com Charaudeau (1983), as estratégias de poder, exercidas em uma sociedade, são o resultado de um jogo do ser e do parecer entre o estatuto social dos sujeitos do circuito comunicativo (EUc/TUi) e o estatuto linguageiro dos sujeitos que constroem a manifestação linguageira (JEe/TUd). E isso nos remete aos papéis que são desempenhados no processo de comunicação.

\section{Referências}

AQUINO, Groppa Julio. Confrontos na sala de aula. Uma leitura 


\begin{tabular}{|l|l|l|l|l|l|l|}
\hline InterteXto & Uberaba & UFTM & $\begin{array}{l}\text { v. 3 } \\
\text { n. } 1\end{array}$ & p. 5-23 & 2010 - jan. / jun. & ISSN 1981-0601 \\
\hline
\end{tabular}

institucional da relação professor-aluno. São Paulo: Summus editorial, 1996.

AQUINO, Groppa Julio. Indisciplina na escola: alternativas teóricas e práticas.

4.ed. São Paulo: Summus editorial, 1996.

BEACCO, Jean-Claude; MOIRAND, Sophie. "Autor des discours de transmission de connaissances", In: Langages. Paris, Didier Érudition, $\mathrm{n}^{\circ}$ 117, 1995, p.32-53.

CHARAUDEAU, Patrick. Langage et discourse: Elements de sémiolinguistique (Théorie et practique). Paris: Hachette, 1983.

CHARAUDEAU, Patrick. Grammaire du sens et de l'expression. Paris: Hachette, 1992.

CHARAUDEAU, Patrick.. Visadas discursivas, gêneros situacionais e construção textual. In: MACHADO, I. L. \& MELLO, R. (orgs) Gêneros: Reflexões em Análise Discurso. Belo Horizonte: NAD/FALE/UFMG, 2004, p.1341.

CHARAUDEAU, Patrick, MAINGUENEAU, Dominique. Dicionário de Análise do Discurso. São Paulo: Contexto, 2004. (Coord. de trad. Fabiana Komesu), pp.334-338.

EMEDIATO, Wander. Os gêneros discursivos como tipos situacionais. In: MARI, H. et alii. Análise do discurso em perspectivas. Belo Horizonte: FALE/UFMG, 2003, p.63-72.

EMEDIATO, Wander. Organização enunciativa e modalização no discurso didático. In: Língua (gem), texto, discurso, v.1: entre a reflexão e a prática/ Gláucia Proença Lara (Org.) - Rio de Janeiro: Lucena: Belo Horizonte, MG: FALE/UFMG, 2006, p.137-154.

FURLANI, Lúcia Maria Teixeira. Autoridade do professor: meta, mito ou nada disso? São Paulo: Cortez, 1988 (Coleção Polêmicas do nosso tempo, v. 28).

GNERRE, Maurizzio. Linguagem, escrita e poder. 4.ed. São Paulo: Martins 


\begin{tabular}{|l|l|l|l|l|l|l|}
\hline InterteXto & Uberaba & UFTM & $\begin{array}{l}\text { v. 3 } \\
\text { n. 1 }\end{array}$ & p. 5-23 & 2010 - jan. / jun. & ISSN 1981-0601 \\
\hline
\end{tabular}

Fontes, 1998. - (Coleção Texto e linguagem).

VION, Robert. La gestion pluridiomensionnelle du dialogue, In: Cahiers de Linguistique Française, nº 17, p.182, 1995. 